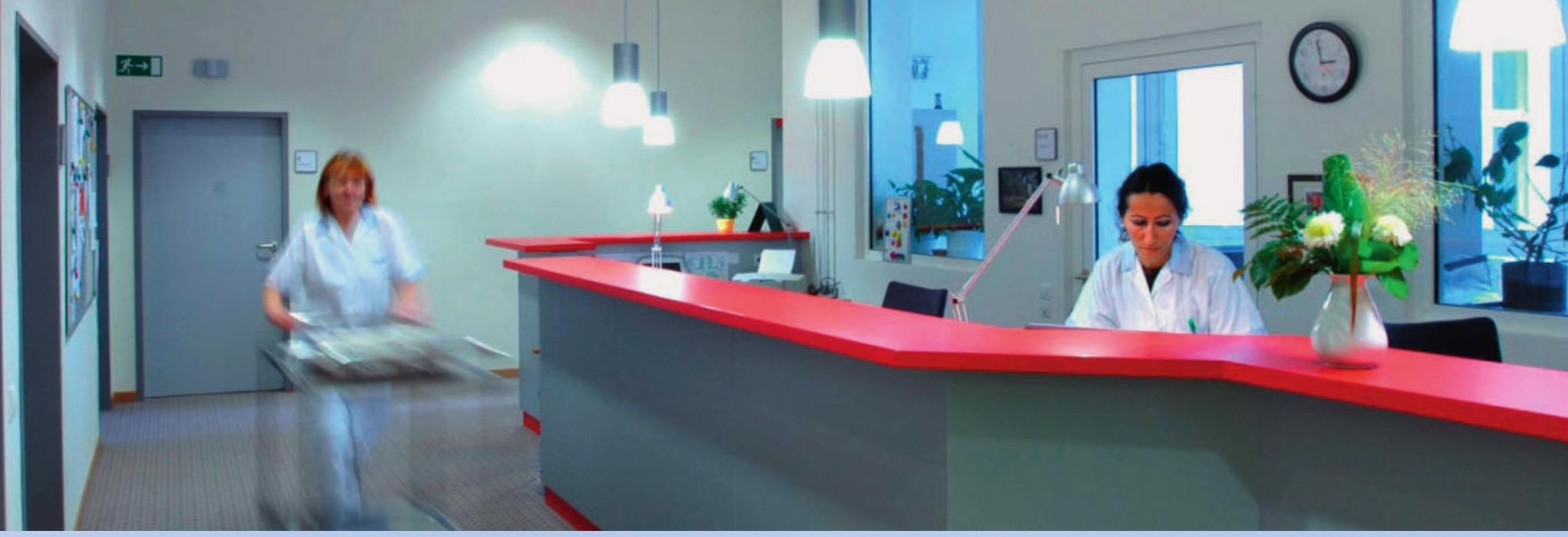

\title{
Remise et reprise de cabinets médicaux
}

\author{
FMH Consulting Services réunit au bon moment vendeurs et acquéreurs de cabinets
}

\section{Recherche d'un successeur}

Le passage à I aretraite, accompagné de la vente du cabinet, n'est pas facile et nécessite des démarches complexes. II est donc particulièrement important de planifier ces démarches de manière consciencieuse et en temps utile. Elles seront couronnées de succès dans la mesure où elles auront été effectuées de manière professionnelle.

\section{"FMH Consulting Services vous aide à planifier et à réaliser votre projet."}

"Comment puis-je trouver un acquéreur approprié pour mon cabinet?" Pour effectuer cette recherche avec succès, il faut connaître parfaitement le marché, disposer d'une documentation professionnelle, estimer la valeur entrepreneuriale du cabinet, mener des activités publicitaires, conclure un contrat et régler le financement avec le successeur.

FMH Consulting Services dispose d'un large réseau ainsi que d'une banque de données complète et régulièrement mise à jour. Grâce à notre longue expérience, nous vous fournissons notre soutien dans toutes les démarches d'une recherche ciblée d'un successeur et dans son choix.

\section{Recherche d'un cabinet}

"Poursuivre mon activité en tant que médecin hospitalier ou me rendre indépendant et détenir mon propre cabinet?" Chaque médecin se pose cette question un jour ou l'autre. La reprise d'un cabinet place vendeurs et acquéreurs face à des défis élevés. II leur faut élaborer et définir des objectifs, analyser le marché et examiner les objets possibles. La recherche d'un cabinet est donc un projet dispendieux en temps et en coûts, impossible à réaliser parallèlement à une activité professionnelle menée à plein temps.

"Forte de sa longue expérience, FMH Consulting Services vous offre u nsoutien éprouvé et effectue les recherches à votre place."

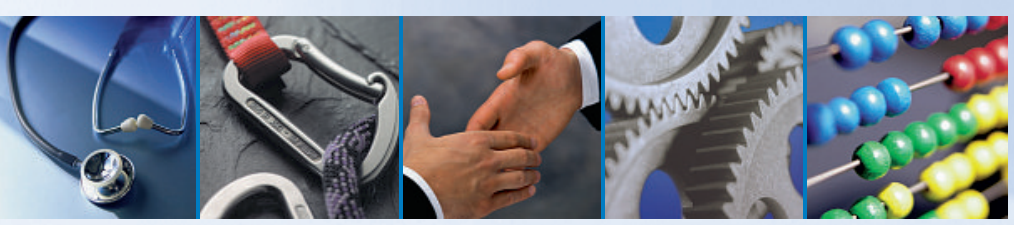

\section{Estimation du cabinet}

Avez-vous besoin d'une estimation professionnelle et d'une documentation pour vous préparer à la vente de votre cabinet? Pas de problème! Nous procédons au calcul de sa valeur et nos chiffres, qui sont reconnus, vous documentent de manière complète et conforme au marché.

"FMH Consulting Services offre u nsoutien professionnel éprouvé dans la recherche d'un successeur ou d'un cabinet médical"

Pour que vos démarches soient couronnées de succès, FMH Consulting Services vous offre les prestations suivantes:

- Recherche d'un successeur avec estimation du cabinet (estimation du goodwill et de l'inventaire)

- Recherche d'un successeur avec estimation du goodwill ou de l'inventaire

- Recherche d'un successeur

- Recherche d'un cabinet médical

- Estimation du cabinet médical

(estimation du goodwill ou de l'inventaire)

N'hésitez pas à étudier notre offre et à nous téléphoner. Nous nous ferons un plaisir de vous offrir nos services.

\section{www.fmhprax.ch -}

le marché des cabinets médicaux

Vous trouverez sur notre site internet les offres actuelles d'achat et de vente de cabinets. \section{GMH CONSULTING}

FMH Consulting Services

Burghöhe I • Case postale 246 6208 Oberkirch Téléphone 04I 9250077 • Fax 04। 9210586 mail@fmhconsulting.ch • www.fmhconsulting.ch 